\title{
Histeria e diagnóstico psiquiátrico na contemporaneidade: tensões com a psicanálise
}

\author{
Hysteria and psychiatric diagnosis in contemporary times: tensions with Psychoanalysis
}

\author{
Fuad Kyrillos Neto ${ }^{[a]}$, Carlos Lemes e Silva ${ }^{[b]}$, \\ Aquinoã Abigail Pederzolicc, Maria Luísa Azôr Hernandes ${ }^{[d]}$
}

\footnotetext{
${ }^{[a]}$ Doutor em Psicologia Social, professor adjunto do Departamento de Psicologia da Universidade Federal de São João del-Rei (UFSJ), São João del-Rei, MG - Brasil, e-mail: fuadneto@ufsj.edu.br

${ }^{[b]}$ Acadêmico do curso de Psicologia da Universidade Federal do Triângulo Mineiro (UFTM), Uberaba, MG - Brasil, e-mail: carloslemes.uftm@gmail.com

${ }^{\text {[c] }}$ Acadêmica do curso de Psicologia da Universidade Federal do Triângulo Mineiro (UFTM), Uberaba, MG - Brasil, e-mail:aquinoa_ped@hotmail.com

${ }^{\text {[d] }}$ Acadêmica do curso de Psicologia da Universidade Federal do Triângulo Mineiro (UFTM), Uberaba, MG - Brasil, e-mail: maluhernandes@yahoo.com.br
}

Recebido: 23/03/2012 Received: 03/23/2012

Aprovado: 16/10/2012 Approved: 10/16/2012

\section{Resumo}

Este trabalho apresenta uma breve apresentação crítica da história do DSM. A partir de fragmentos de um caso clínico atendido em um Centro de Atenção Psicossocial (CAPS) e com base nas controvérsias criadas em torno da classificação DSM, faz-se uma comparação entre um diagnóstico concebido pelo DSM e um diagnóstico realizado pelo viés da Psicanálise com o objetivo de demonstrar que diferentes razões diagnósticas acarretam distintas conduções do tratamento. Demonstram-se ainda as consequências clínicas do modus operandi da Psicanálise com o sujeito histérico, cujo cerne é fazer emergir o sujeito a partir de sua fala. Apontam-se algumas consequências da razão diagnóstica predominante na Psiquiatria contemporânea com sua lógica diagnóstica que desconhece a singularidade do sujeito em seu jogo com o sintoma. Conclui-se que o sintoma histérico pode funcionar como um convite para que o médico ocupe uma posição subjetiva em relação ao sujeito, afastando-se do discurso científico e objetivo, característico da instituição médica.

Palavras-chave: Psicanálise. DSM. Diagnóstico. Histeria.

\section{Abstract}

This paper presents is a brief critical presentation of the history of DSM. From fragments of a clinical case treated at a Psychosocial Care Center (CAPS) and based on the controversy created around the DSM classification, it is performed a comparison between diagnosis made from the perspective of DSM and Psychoanalysis in order to demonstrate that different diagnostic reasons entail distinct clinical interventions. We also demonstrate the clinical consequences of the Psychoanalysis modus operandi with the hysterical subject, whose core is to emerge the subject from his/her speech. We point out some consequences of the prevailing diagnostic reason in contemporary psychiatry with its diagnostic logic that ignores the singularity of the subject in his/ her game with the symptom. We conclude that the hysterical symptom may work as an invitation for the physician to occupy a subjective position in relation to the subject, thus departing from the scientific and objective discourse, which is characteristic of the medical institution.

Keywords: Psychoanalysis. DSM. Diagnosis. Hysteria. 


\section{Breve apresentação crítica do DSM}

Este artigo constitui-se em uma comunicação preliminar das reflexões que estão sendo elaboradas na investigação intitulada A psicopatologia e o DSM IV: um diálogo com a Psicanálise. Iniciada em abril de 2011, a pesquisa tem como objetivo discutir os critérios diagnósticos em Psiquiatria e Psicanálise a partir de estudos de casos assistidos pela equipe de um Centro de Atenção Psicossocial (CAPS) e suas implicações na condução clínica do caso, mapeando os estudos acerca das relações entre a classificação DSM, a Psiquiatria e a Psicanálise produzidas no Brasil. Além disso, por meio dessa pesquisa pretende-se observar as divergências e convergências entre a teoria do DSM e a psicopatologia psicanalítica a partir de estudos de caso assistidos pela equipe de um CAPS municipal e modular, uma linha de debate entre a Psicanálise e o sistema de classificação DSM em bases que superem as proposições de caráter político, ideológico e até mercadológico.

De Pinel (1809) e Bleuler (1955) até os dias atuais, a classificação de transtornos mentais insiste em "importunar" a sociedade implicada na clínica e estudo das doenças psiquiátricas (Pessoti, 1999). Atenta-se aqui na decorrência desse efeito, o Manual Diagnóstico e Estatístico de Transtornos Mentais (DSM). Ele foi criado a partir da demanda de coletar informações estatísticas sobre as doenças e transtornos mentais e da necessidade de criação de uma linguagem de comum entendimento acerca das classificações dos transtornos mentais e possibilidades de diagnóstico entre todos os estudiosos e clínicos da área de saúde mental.

Na década de 1840, nos Estados Unidos, surgiu a necessidade de catalogação e coleta de dados estatísticos acerca dos transtornos mentais por causa da frequência do aparecimento do idiotismo/ insanidade, fomentada primeiramente pela antiga Associação Médico-Psicológica Americana - hoje chamada de Associação Psiquiátrica Americana. Os dados com caráter estatístico coletados também foram tomados em um aproveitamento prático na clínica. 0 primeiro desenvolvimento de uma nomenclatura psiquiátrica dessa instituição se deu com o apoio da Academia de Medicina de Nova York, foi anexada à Nomenclatura Classificada e Estandardizada das Doenças da Associação Médica Americana e tinha como objetivo o diagnóstico de pacientes internados com transtornos psiquiátricos e neurológicos graves (American Psychological Association [APA], 2002).

Com a necessidade de uma terminologia mais complexa das doenças mentais para a triagem dos quadros apresentados nas clínicas pós-Segunda Guerra Mundial, o exército dos Estados Unidos desenvolveu uma classificação mais completa, incluindo termos como transtornos psicofisiológicos de personalidade e agudos (APA, 2002). Pode-se dizer que o movimento inicial do DSM concentra-se nesse episódio de classificação.

A Organização Mundial de Saúde (OMS), ao desenvolver a sexta versão do CID (Catálogo Internacional de Doenças), incluiu pela primeira vez uma sessão específica para os transtornos mentais, sendo extremamente influenciada pelo manual do exército americano. Portanto, a hoje chamada American Psychological Association (APA) foi o primeiro Manual Estatístico de Transtornos Mentais (DSM-I), editado em 1952. Esse manual foi influenciado principalmente pelos ideais da perspectiva psicobiológica de Adolf Meyer: os transtornos mentais representariam reações da personalidade a fatores psicológicos, sociais e biológicos.

A partir de então, os colaboradores das reedições do CID e do DSM trabalharam juntos para evolução de ambos, sempre trocando informações e realizando recomendações mútuas. A segunda versão do manual, o DSM-II, foi lançada em 1968, com uma alteração fundamental: a descrição de síndromes mentais como "reações" para doenças, promovendo um alinhamento mais restrito da Psiquiatria americana com a Medicina (Tomm, 1990). A segunda versão do DSM refletia a predominância da psicodinâmica psiquiátrica, embora a perspectiva biológica de Kraeplin ainda permanecesse incluída - os sintomas vistos como reflexos de grandes conflitos ou reações inadequadas aos problemas da vida (Dunker \& Kyrillos Neto, 2011).

No DSM-II também pode-se perceber uma ilustração de como a Psiquiatria ainda se apresentava de forma normativa e utilizava conceitos psicanalíticos de forma retrógada: "a cooptação entre histeria e feminilidade ou homossexualidade e perversão é exemplo de que o manual representaria a realização institucional referendada pelo Estado e articulada aos seus dispositivos educacionais, jurídicos e de pesquisa com viés político" (Dunker \& Kyrillos Neto, 2011, p. 614). 
O DSM-III surgiu como resultado de uma força-tarefa de diversos pesquisadores, clínicos e profissionais da área de transtornos mentais. Ele tinha como principal objetivo uma aplicabilidade clínica e estatística para todos os usuários do manual, oferecendo nomenclaturas e categorias que facilitassem o método estatístico de coleta de dados. Segundo Tomm (1990), a prioridade dessa versão foi a precisão e a exatidão nos diagnósticos. Isso baseado no pressuposto médico de que o planejamento do tratamento deve começar com uma avaliação médica precisa. No entanto, a preocupação estava voltada para dados empíricos em detrimento do humanismo. Logo, o DSM-III foi baseado em pesquisas o tanto quanto possível, retirando significativamente a influência de médicos com experiência terapêutica e aumentando os "dados por pesquisa". Contudo, algumas inconsistências foram apontadas pela APA oito anos após a publicação do DSM-III, e um novo grupo de trabalho foi escalado para a revisão do manual.

O DSM-III e sua reedição, o DSM-III-R, foram criados com uma ideologia estritamente ateórica e com uma abordagem predominantemente descritiva. Todavia, Tomm (1990) alerta:

Os autores pareceram não perceber a importância teórica de seus pressupostos individualistas. Não houve nenhuma menção de uma possibilidade de outro ponto de vista. Eles simplesmente ignoraram o corpo do conhecimento com base em uma hipótese alternativa, ou seja, que o comportamento humano, a mente e seus distúrbios, pode ser mais fundamentalmente baseado em fenômenos sociais do que os fenômenos individuais. (p. 2)

Uma perspectiva semelhante é adotada por Mishara (1994) ao explanar sobre a importância da subjetividade do paciente para a pesquisa em doenças mentais e classificação. 0 autor aponta que a subjetividade é geralmente concebida como o inverso da noção de objetividade em observação e mensuração. Para ele, "a abordagem descritiva do DSM-III-R teve sua lealdade com o ponto de vista comportamental ocultado, para o manual é preferivel minimizar as inferencias sobre a subjetividade do paciente" (Mishara, 1994, p. 130). Existem elementos da teoria comportamental, embora eles estejam ocultados sob a ideia ateorica do manual, levando a um erro filosófico na constituição do manual.

Samuel-Lajeunesse, Olivier-Martin, Ginestet, Simon e Wartel (1989) adotam uma postura crítica perante o DSM. Os pesquisadores chamam atenção para a ocorrência de que não há interpretações clínicas dentro do DSM a partir do fato de que a formação dos critérios parte de uma homogeneização dos diagnósticos de forma mais determinada e objetiva possível, tornando impossibilitada a interferência e interpretação do clínico.

O DSM trás uma discussão acerca da definição de transtorno mental. Para o manual, é uma infelicidade o anacronismo entre a definição de transtorno físico e mental, que se torna reducionista em relação ao dualismo mente/corpo (APA, 2002). Várias abordagens tentam contornar o problema dessa definição, mas não chegam a um acordo ou resultado comum. Para o DSM, um transtorno mental é composto por uma síndrome ou padrão de comportamento psicológico clinicamente importante que se manifesta no indivíduo e gera algum sofrimento físico, mental ou prejuízo social.

Sobre a questão relativa ao uso diagnóstico do DSM, sua quarta versão faz uma advertência em torno da problemática da classificação. Não é por apresentar um determinado diagnóstico que um indivíduo é taxado pelo nome do transtorno. Por essa razão, o DSM não apresenta a redação "indivíduo esquizofrênico", mas "indivíduo com esquizofrenia". 0 manual não coloca os indivíduos classificados com o mesmo transtorno como se fossem semelhantes, tratados da mesma forma por possuírem a característica em comum. Porém, Tomm (1990) faz uma ácida crítica para essa explicação, relatando a incidência dos códigos da classificação do manual na sociedade: "A maioria dos sistemas de saúde na America do Norte adotaram o DSM, e em muitos casos não é possível receber o pagamento sem que seja apresentado um diagnóstico" (p. 3). Essa prática de rotulagem decorre do ideal de que o transtorno está na pessoa.

No Brasil, foram desenvolvidas pesquisas envolvendo as tensões existentes entre a razão diagnóstica do DSM e a Psicanálise. Pereira (2011) faz referências às implicações do uso do DSM na Psiquiatria, enfatizando a perda do objeto da psicopatologia nessa classificação. Figueiredo e Tenório (2002) apontam a diferença de diagnósticos produzidos pelo DSM e pela Psicanálise em relação 
a um caso atendido no Instituto de Psiquiatria da Universidade Federal do Rio de Janeiro que foi discutido em uma apresentação de enfermos conduzida por um psicanalista. Nesse debate, evidenciou-se uma tendência atual da Psiquiatria em substituir as grandes categorias classificatórias (neurose, psicose, esquizofrenia) por descrições especificadas de fenômenos objetivos, trazendo um empobrecimento à lógica diagnóstica psiquiátrica, pois se privilegia a descrição dos sintomas ao invés da patologia.

Tem-se ainda a obra organizada por Jerusalinsky e Fendrik (2011), intitulada O livro negro da psicopatologia contemporânea. A obra denuncia a patologização da vida humana e um uso indiscriminado, abusivo e cada vez mais precoce de psicofármacos. Os organizadores destacam que:

A ligeireza (e imprecisão) com que as pessoas são transformadas em anormais é diretamente proporcional à velocidade com que a psicofarmacologia e a Psiquiatria contemporânea expandiram seu mercado. Não deixa de ser surpreendente que o que foi apresentado como avanço na capacidade de curar tenha levado a ampliar em uma progressão geométrica a quantidade de "doentes mentais". (Jerusalinsky \& Fendrik, 2011, p.6)

Advertido das controvérsias criadas em torno da classificação DSM, este artigo se dispõe a comparar o diagnóstico concebido pelo DSM a partir de fragmentos de um caso clínico a ser apresentado e um diagnóstico pelo viés da Psicanálise. Espera-se, com isso, não criar uma comparação sobre qual é o melhor diagnóstico, mas apresentar como diferentes razões diagnósticas acarretam distintas conduções do tratamento. Serão demonstradas ainda as consequências clínicas do modus operandi da Psicanálise, cujo cerne é fazer emergir o sujeito a partir de sua fala.

\section{Fragmentos dínicos do caso}

Através da discussão de vinhetas clínicas de um caso atendido em um CAPS, a intenção é apresentar a razão diagnóstica da Psiquiatria pautada no DSM e da Psicanálise, tencionando ambas e demonstrando a importância diagnóstica na condução do caso clinico, sendo que não se pretende realizar um embate teórico entre estas, mas proporcionar duas análises diagnósticas distintas. Para a realização desse intento, apresentam-se alguns fragmentos do caso de Mônica. ${ }^{1}$ Trata-se de uma jovem atendida em um CAPS por apresentar comportamentos de risco que causam preocupação em sua família. Sua mãe já havia morrido, e com a morte de seu pai mudou-se de cidade e passou a morar com o irmão mais novo. Por morar perto da casa deles, o irmão mais velho observa que os dois não sabem administrar a casa sozinhos e que ela não tem noção de dinheiro, dorme com a porta aberta e fala muito do passado. Os familiares a consideravam "normal" até seu filho nascer.

Mônica sente muita falta do pai e conversa com a mãe. Desde que esta morreu, começou a frequentar uma boate. Afirma que vai por vontade própria, que "quis ir.... Ela tem muitos conflitos com o irmão com quem mora, é persecutória em relação ao marido, diz que ele bate nela - "se bate é porque ama, né?" - e lhe fez um filho. Relata que sente o cheiro do ex-namorado no cobertor.

Segundo a paciente, aos 12 anos sentia medo porque os homens a olhavam com cobiça. Ela conta que certa vez teve relação sexual forçada com um parente, sentindo-se muito mal. Mônica fantasia que homens invisíveis entram em sua casa à noite $\mathrm{e}$ batem-na. Em um momento, diz que está sangrando e pergunta se é câncer, diz estar com tremores nas mãos e que tem um dente sangrando - passa o dedo no dente e mostra-o sem sangue. Diz que toma anticoncepcional, mas que no dia anterior não tomou e pergunta o que deve fazer. Afirma que gosta de fingir e pondera se faz isso por não estar bem. Fala muito sobre doenças.

A paciente disse que os homens no CAPS querem transar com ela, mas ela não, e pergunta o que deve fazer. Quando questionada se ela se coloca no lugar de mulher desejável, ri e fala que precisa pensar. Acha-se feia, queria ser diferente, sente-se acabada, mas diz que salão e academia são muito caros. Gostava de ir à boate para ver se algum homem a deseja e conta que passou seis dias lá, sem dormir, bêbada e que não sabe o que fizeram com ela.

Mônica sente-se triste por não ter casado oficialmente, diz que sente falta do ex-namorado, que é casado, mas que também errou com ele. Pergunta

\footnotetext{
${ }^{1}$ Foi usado o nome fictício de Mônica para preservar a identidade da paciente.
} 
se deve procurá-lo e se deve se masturbar, pois está sentindo falta de amor e sexo. Sente-se ansiosa, com vontade de transar, atribuindo essa ansiedade à falta de sexo, mas diz que não é por prazer. Também fica ansiosa por querer mais pessoas a atendendo; diz que queria dois psiquiatras, porque ela "não é fácil". Quando indagada por que quer todos voltados para ela, ri.

A paciente tem dificuldades em lidar com o filho, que mora com ela. Não perdoa o pai dele, que a abandonou. Diz gostar de ser menina, pois é difícil ser mãe. Fala que talvez quisesse ser homem, porque "homem é forte".

\section{Mônica na perspectiva do DSM}

Buscando uma práxis clínica e de pesquisa, o DSM se divide em cinco eixos compostos na seguinte forma:

Eixo I - transtornos geralmente diagnosticados pela primeira vez na infância ou adolescência;

Eixo II - transtornos da personalidade/retardo mental;

Eixo III - condições médicas gerais (com equivalência de códigos com a CID-9);

Eixo IV - problemas psicossociais e ambientais;

Eixo V - designado de Avaliação Global das Funções.

De acordo com esses eixos e tendo em pauta toda a história clínica de Mônica, pode-se realizar um diagnóstico pelo DSM, decompondo-o pelos eixos apresentados acima e pela semiologia dos sintomas captados a partir do caso em questão.

O Eixo I, de transtornos geralmente diagnosticados na infância, sugere para Mônica um diagnóstico de: delirium por intoxicação com álcool: 291.0 - a paciente apresenta algumas ideias delirantes com a presença do álcool; esquizofrenia do tipo indiferenciado: 295.90 - ela preenche os principais sintomas apresentados pelo DSM para o diagnóstico de esquizofrenia.

Já no segundo eixo, transtornos da personalidade/retardo mental, pode-se classificar o caso como transtorno da personalidade paranoide (301.0) e transtorno da personalidade histriônica (301.5).

No Eixo IV, pode-se visualizar que Mônica sofria com seu ambiente familiar, ou seja, seu grupo primário de apoio - o que também é previsto pelo DSM como um critério importante para se estabelecer um diagnóstico completo em saúde mental.
Com a propriedade apresentada no manual de se agrupar diagnósticos a partir dos eixos, o diagnóstico de Mônica em sua versão final e completa com todos os eixos incluídos é: esquizofrenia do tipo indiferenciado (295.90) com delirium por intoxicação com álcool (291.0), transtorno da personalidade histriônica (301.5) com problemas no grupo primário de apoio.

\section{0 viés psicanalítico}

Quando o indivíduo abdica do objeto edipiano, livrando-se da angústia de castração, lhe é possível voltar-se para outros objetos e afirmar-se sem o receio da sua rivalidade com o progenitor do mesmo sexo. Ou seja, para isso é necessária a dissolução do Édipo. Os resultados da resolução da crise edipiana envolvem, de um lado, a sobrevivência do desejo edipiano e, de outro, a subtração do perigo da castração. A solução que o indivíduo achar para esses dois impasses determinará sua estrutura (neurose, psicose, perversão). No caso das neuroses, em todas as suas manifestações, tem-se a expressão de um desejo e de uma defesa. Conforme a natureza desse desejo e o modo de defesa adotado, bem como as identificações por meio das quais se institui a estrutura da personalidade, se dará a neurose correspondente (Brabant, 1973).

As psiconeuroses partilham dos mesmos processos psíquicos durante seus percursos, porém a histeria tem uma característica que a diferencia das demais: a complacência somática, dado que a exigência de todo sintoma histérico é a participação dos dois lados, o psíquico e o somático, em sua origem (Freud, 1912/2010). A partir disso, discute-se o caso de Mônica como uma neurose histérica, começando por destacar como a complacência somática aparece em todas as suas falas sobre doenças, uma vez que os processos inconscientes encontram uma saída no corpo.

A vida sexual do histérico caracteriza-se por um paradoxo marcado pela coexistência de um corpo globalmente erotizado e uma inibição da zona genital - há ao mesmo tempo uma necessidade sexual excessiva e uma rejeição da sexualidade. Quando Mônica diz que está com vontade de transar, mas que não é por prazer, é possível observar como o histérico, ao criar sinais sexuais, acredita e leva o outro a acreditar que realmente deseja consumar o 
ato sexual. Porém, esses sinais dificilmente levarão a paciente realizar essa ação, revelando o verdadeiro desejo do histérico: o fracasso desse ato.

Na histeria, a sedução é colocada não a serviço do desejo, mas do falo. 0 histérico goza ao produzir esses sinais, como um gozo masturbatório. Ele prefere a masturbação ao perigo oferecido pela relação sexual, vive a sexualidade por todo o corpo não genital, que é erotizado e sofre excitações sexuais constantes, em vez do gozo da penetração. A mulher histérica renuncia esse gozo e sua sexualidade genital, pois ser penetrada significa desintegrar seu corpo (Nasio, 1991).

A erotização das relações sociais provoca o sofrimento de ter de experienciar o encontro genital com o sexo oposto. Essa erotização chama-se histericização, em que o histérico sexualiza o que não é de natureza sexual, percebendo conteúdos sexuais em palavras, gestos ou até mesmo no silêncio do outro ou que dirija ao outro (Ibid.).

Para Freud (1901/2010), "inversão do afeto" é um mecanismo de defesa que desperta sentimentos desprazerosos em uma histérica diante de uma excitação sexual, independente de a pessoa ser capaz de produzir sintomas somáticos. Observa-se isso na fala da paciente quando afirma que se sentiu muito mal após a ocasião em que um parente a pegou à força para a relação sexual e que aos 12 anos sentia medo, pois os homens a olhavam com cobiça. Ainda segundo Freud, a aversão aos homens possivelmente excitados sexualmente segue o mecanismo da fobia, um sintoma psíquico, cuja função seria fornecer proteção contra o renascimento de uma percepção recalcada. Essa percepção corresponderia ao recalque de Mônica diante da possibilidade de sentir prazer sexual naquela circunstância vivida com seu familiar.

Paralelamente a esses fatos, a paciente afirma que gosta de ir à boate "para verificar se algum homem a deseja". Freud (1914/2010), em Introdução ao narcisismo, faz uma interessante digressão acerca da escolha de objeto nas mulheres:

De outro modo se configura o desenvolvimento no tipo mais frequente e provavelmente mais puro e genuíno de mulher. Com a puberdade, a maturação dos órgãos sexuais femininos até então latentes parece trazer um aumento do narcisismo originário, que não é propício à constituição de um regular amor objetal com superestimação sexual. Em particular quando se torna bela, produz-se na mulher uma autossuficiência que para ela compensa a pouca liberdade que a sociedade lhe impõe na escolha de objeto. A rigor, tais mulheres amam apenas a si mesmas com intensidade semelhante a que são amadas pelo homem. Sua necessidade não reside tanto em amar quanto em serem amadas, e o homem que lhes agrada é o que preenche tal condição. (p. 33-34)

A citação evidencia a lógica histérica, não de todo fálica. Não há deslocamento de objeto fálico, mas uma identificação naquilo que falta ao outro. Ela quer ter o falo e mantém-se em permanente demanda por ele. Freud falava do narcisismo voltado para o corpo da mulher pós-pubescente como ressarcimento pela atrofia no terreno da escolha de objeto. Para Alonso e Fucks (2004), o centramento da identidade feminina no corpo e nas capacidades de reprodução produz como efeito o lugar oposicionista da histérica que não aceita a carência do órgão, de significante, nem o lugar de objeto causa de desejo e rivaliza constantemente com o falo e com aquele que supõe que o tem.

Percebe-se como a influência e a sugestão operam em Mônica principalmente quando coloca seu terapeuta em um lugar privilegiado, elegido como "senhor". Assim, ao perguntar sempre o que deve fazer - se deve se masturbar, procurar o ex-namorado -, ela mostra como ele torna-se o suposto saber sobre a questão que se empenha em não reconhecer a questão de seu desejo.

Mônica também se vê em um lugar de medo quando tinha 12 anos e os homens a olhavam com cobiça. Como atenta Nasio (1991): "mais do que um sedutor, o histérico é um ser de medo" (p. 113), pois existe um perigo do qual ele tem de se proteger: gozar, e para isso mantém um doloroso estado de insatisfação. No que tange às relações sexuais, a histérica pode até se oferecer ao orgasmo, mas se furta à entrega, ao que o autor denomina "gozo do aberto", o qual seria diferente, misterioso e perigoso. Assim, a plena satisfação em qualquer instância de sua vida se encontra impossibilitada e pode se manifestar por episódios depressivos - quando Mônica afirma ter apresentado depressão pós-parto.

Paradoxalmente, o sujeito histérico pode transformar a "dor de insatisfação" em "desejo pela insatisfação", denominado por Lacan de "desejo de insatisfação". Estar e se manter insatisfeito proporciona ao histérico a inviolabilidade fundamental de seu 
ser, se constituindo na proteção contra um gozo que para ele represente a possibilidade de desintegração ou loucura. Mônica, apesar de se sentir acabada e feia, nunca se posiciona no sentido de contornar sua autoimagem negativa em busca de cuidado em relação a sua aparência física. Ela afirma que salão e academia são caros e sempre pensa em se relacionar com homens casados para nunca ter um relacionamento estabelecido e satisfatório. Há uma recusa em sentir-se bem e completa consigo mesma e em relacionamentos. Ela busca inclusive fingir - gosta disso e finge por não estar bem - como manobra para se manter inconscientemente insatisfeita e evitar o medo de um gozo pleno, por esse ser algo assustador e fonte de ansiedades angustiantes.

Dor (1993) também aborda a questão do "cuidado de perfeição", o qual atordoa a histérica sem descanso. Segundo o autor, a preocupação com a beleza subjugada ao ideal de perfeição se mantém expressa de forma negativa. Mônica mostra essa condição quando afirma achar-se feia, acabada e desejar ser diferente, comportamento típico advindo da insatisfação natural da histérica no sentido de não correr atrás de um desejo, mas de um ideal.

A mulher histérica, a fim de proteger a representação imaginária do homem ideal, sustentando a ilusão de que esse homem escolhido não lhe causará desapontamento, lida com o fato de modo pragmático: escolhe um parceiro amoroso distante ou inacessível. Dessa forma, ele se mostrará como o único que convém, uma vez que será o homem de outra mulher. Mônica diz sentir falta do ex-namorado, que é casado. Logo, ele se revela como o homem ideal para ela justamente porque, entre todos os parceiros masculinos, o que ela quer é o inacessível. Assim, ela pode desconsolar-se. Seguindo essa estratégia, a paciente pode conservar seu desejo, visto que satisfazê-lo também implica sua perda (mesmo que momentânea), mantendo-se insatisfeita.

De acordo com Dor (1993), o histérico pode apresentar a chamada alienação subjetiva na relação com o desejo do outro, fato perceptível na sujeição do desejo que se possa pressentir e até imaginar que exista por parte do outro. Essa sujeição favorece, através de um excesso de imaginário, a construção de sugestão. Essa alienação subjetiva pode ser observada quando Mônica afirma que outros usuários do CAPS estão "dando em cima" dela, pois ela supõe que esses pacientes estão interessados sexualmente por ela. No entanto, quanto o terapeuta lhe pergunta se ela não estaria se colocando nesse lugar de desejo do outro, ela afirma que precisa pensar a respeito disso.

Segundo Nasio (1991), o histérico, apresentando uma fixação no estádio fálico, se encontra em dificuldade de distinguir o sexo masculino e o feminino, pois esse impasse é característico da fase fálica de desenvolvimento na criança. No entanto, isso se torna uma incerteza sexual que perpetua no sujeito histérico, visto que ele não logrou passar por esse estádio. Mônica apresenta o desejo de ser um homem, pois, segundo ela, "homem é forte". Ao mesmo tempo, a paciente afirma gostar de ser menina, criança, pois é difícil ser mãe, denotando, assim, um problema de satisfação em relação a sua identidade sexual.

\section{Considerações finais: a histeria e a razão diagnóstica predominante na Psiquiatria contemporânea}

Considerando-se o advento da ciência como um pilar da modernidade, é possível posicionar o saber do "mestre antigo" (a opinião e a realidade socialmente construída) como permanentemente em questão. Freud, em sua prática psicanalítica, apontava como as histéricas, na condição de sujeito dividido, interrogam seus mestres, expondo as falhas de seus saberes. Antes de Freud, o saber psiquiátrico já encontrava dificuldades em decifrar o enigma do sintoma histérico. A Psicanálise revela que os sintomas da histeria obedecem às leis da linguagem $\mathrm{e}$ podem ser afetados pela interpretação de seu sentido inconsciente.

Os fragmentos clínicos de Mônica, apresentados em uma supervisão institucional como um caso considerado "difícil" pela equipe de um serviço aberto de saúde mental, mostra o risco de se operar com uma lógica diagnóstica que desconhece a singularidade do sujeito em seu jogo com o sintoma. 0 caso em questão, diagnosticado com base em evidencias estatísticas, é tratado predominantemente com medicações antipsicóticas e tentativas frustradas de adequação ao meio social.

Constata-se que na contemporaneidade as relações entre a Psicanálise e a Medicina encontram-se comprometidas. Santos e Santiago (2010) apontam três eixos dessa relação conflituosa: o crescimento das abordagens cognitivo-comportamental na Psicologia clínica, a influência da Medicina baseada 
em evidências estatísticas atinentes à abordagem epidemiológica em saúde mental e o crescimento da indústria farmacológica. A partir da consideração de tais fatores, tudo que o sintoma possa comportar de mensagem, de enigma a ser decifrado, tende a ser desconsiderado.

Ramos (2008) lembra que desde os anos de 1950 os autores divulgam a ideia de que a histeria já não é a mesma da época de Charcot e Freud, pois já não se apresenta na forma de sintomas, mas aparece, sobretudo, como uma neurose de caráter. Isso quer dizer que sua manifestação é no modo de ser, e ser é existir em relação ao outro. São pessoas insatisfeitas, que não evitam as relações objetais, mas sofrem muito dentro delas. Esse autor chama a atenção para o fato de que, desde a década de 1950, a histeria se apresenta principalmente na forma de relações conjugais conturbadas, então é bastante chamativo que tanto a teoria psicanalítica quanto o fenômeno analisado por ela caminharam, depois de Freud, no sentido de enfatizar as relações.

A partir da assimilação dos três eixos anteriormente expostos, a dimensão real do sintoma modifica no transcorrer dos tempos históricos. Dizer que a clínica muda é apostar na transformação do sintoma. Embora o sintoma seja uma mensagem com estrutura de metáfora, seu envoltório formal está condicionado pelas manifestações particulares do mal-estar na civilização.

Dessa forma, como ensinam Santos e Santiago (2010), as manifestações histéricas contemporâneas são consequências das alterações operadas pela ação do discurso no sistema de significantes dos ideais. As formas do sintoma modificam no decorrer do tempo, seguindo o processo de transformação das configurações dominantes do mal-estar na civilização.

Em Psicanálise, o discurso do sujeito é apreendido como um semblante contra o real. As estruturas clínicas não são convenções arbitrárias, pois se ancoram no real.

É importante lembrar que o ponto de vista relacional é adotado pela Psicanálise. 0 psicanalista é comprometido com o trabalho da escuta. Sua concepção de histeria construiu-se não somente por intermédio das obras de Psicanálise, mas, sobretudo, pela experiência de transferência do chamado "analisando histérico".

0 analista não abre mão de ocupar um lugar e de fazer um trabalho que produza uma fala que possa idealmente mostrar algo da posição do sujeito na fantasia. Na apresentação psicanalítica (entrevista), essa fala é produzida em certo registro da transferência, de endereçamento. Nisso reside a tentativa do "mais-além" dos fenômenos, que é a relação, a posição que o sujeito falante ocupa diante do outro. Lembra-se aqui da preponderância da dependência do sujeito histérico ao personagem médico/mestre. Nas vinhetas clínicas estudadas, isso se evidencia em algumas perguntas da paciente sobre o que deve fazer em situações envolvendo sua sexualidade. Trata-se de situações em que o sujeito se beneficia da doença e de seus diversos mal-estares para suscitar o interesse do outro. Os analistas sabem que quando uma histérica é encaminhada ao médico ou o procura, não se deve ter convicção de que ela espera cura. Ela pode desafiá-lo a tirá-la de sua condição de doente, fato que demonstra sua atração pela ideia de conservar seu estado.

Essa possibilidade aponta para o risco da Psiquiatria pautada no DSM: o de constituir uma prática que implica na supressão do sujeito. Essa tese é trabalhada por Clavreul (1983) ao afirmar que o discurso médico é, em sua essência, um discurso próximo do discurso de mestre. ${ }^{2}$ Os psicanalistas sabem que a demanda lançada ao médico, assim como a demanda dirigida ao analista, não é puramente uma demanda de cura. E, no momento que o médico não percebe isso, algo escapa ao tratamento:

Responder que o doente lhes demanda a cura não é responder absolutamente nada, pois a cada vez que a tarefa precisa que deve ser realizada com urgência não corresponde pura e simplesmente a uma possibilidade que se encontre ao alcance da mão - digamos

20 discurso é um modo de relacionamento social representado por uma estrutura sem palavras. Lacan propõe os discursos como modos de uso da linguagem como vínculo social, pois é na estrutura significante que o discurso se funda. Os quatro discursos (do mestre, universitário, da histérica e do analista, além do quinto discurso, o do capitalista) são configurações significantes que se diferenciam e se especificam por sua distribuição espacial. 0 que está em jogo é aquilo que ordena e regula um vínculo social entre os sujeitos. 0 discurso do mestre é reconhecido como um discurso de domínio, um discurso de consciência como dominante, como idêntica ao eu. Lacan (1969-70/1992) aponta que esse discurso funda uma "eucracia". 
um aparelho cirúrgico ou a administração de antibióticos (e mesmo nestes casos resta saber o que disto resulta para o futuro) - algo fica fora do campo daquilo que é medicado pelo benefício terapêutico, algo que se mantém constante e que todo médico sabe bem do que se trata (Lacan, 1966/2001, p. 10).

É a exclusão das posições subjetivas do médico e do paciente o alicerce dessa relação. A partir dessa premissa, o médico intervém e fala como instrumento do discurso médico. Tem-se, assim, uma anulação do médico como sujeito, pois sua prática deve ser pautada na objetividade científica. Porém, a histeria surge mais uma vez na história com um sintoma que coloca o fracasso da ordem médica e, portanto, dessa figura contemporânea do discurso do mestre.

\section{Referências}

Alonso, S. L., \& Fucks, M. P. (2004). Histeria. São Paulo: Casa do Psicólogo.

American Psychological Association - APA (2002). DSMIV-TR Manual Diagnóstico e Estatístico de Transtornos Mentais. (4. ed., C. Dornelles, trad.). São Paulo: Artmed

Brabant, G. P. (1973). Os resultados do conflito. In G. P. Brabant. (Org.), Chaves da Psicanálise (pp. 90-102). Rio de Janeiro: Jorge Zahar.

Clavreul, J. (1983). A ordem médica: poder e impotência do discurso médico. Rio de Janeiro: Brasiliense, 1983.

Dor, J. (1993). Estruturas e clínica psicanalítica. Rio de Janeiro: Taurus.

Dunker, C. L. I., \& Kyrillos Neto, F. (2011). A crítica psicanalítica do DSM: breve história do casamento psicopatológico entre Psiquiatria e Psicanálise. Revista Latino-americana de Psicopatologia Fundamental, $4(14), 611-626$.

Figueiredo, A. C., \& Tenório, F. (2002). 0 diagnóstico em Psiquiatria e Psicanálise. Revista Latino-americana de Psicopatologia Fundamental, 5(1), 29-43.
Freud, S. (2010). Um caso de histeria, três ensaios sobre a sexualidade e outros trabalhos. Rio de Janeiro: Imago. (Originalmente publicado em 1901).

Freud, S. (2010). Introdução ao narcisismo. São Paulo: Companhia das Letras. (Originalmente publicado em 1914).

Jerusalinsky, A., \& Fendrik, S. (2011). O livro negro da psicopatologia contemporânea. São Paulo: Via Lettera.

Samuel-Lajeunesse, B., Olivier-Martin, R., Ginestet, D., Simon, P., \& Wartel, R. (1989) Em torno do DSM III. In Lacan, J. A querela dos diagnósticos (pp.70-83). Rio de Janeiro: Jorge Zahar.

Lacan, J. (1992). O avesso da Psicanálise. Rio de Janeiro: Jorge Zahar. (Original publicado em 1969-70).

Lacan, J. (2001). O lugar da Psicanálise na Medicina. Opção Lacaniana, 32, 8-14. (Original publicado em 1966).

Mishara, A. L. (1994) A phenomenological critique of commonsensical assumptions in DSM-III-R. In: A. L. Mishara. Philosophical perspectives on psychiatric diagnostic classification (pp.129-147). Baltimore/ London: Johns Hopkins University Press.

Nasio, J. D. (1991). A histeria: teoria e clínica psicanalítica. Rio de Janeiro: Jorge Zahar.

Pereira, M. E. C. O DSM IV e o objeto da psicopatologia ou psicopatologia para quê? Recuperado em 15 de maio de 2011, de http://www.estadosgerais.org/ historia/98-dsm-iv.shtml.

Pessoti, I. (1999). Os nomes da loucura. São Paulo: Editora 34.

Ramos, G. A. (2008). Histeria e Psicanálise depois de Freud. Campinas: Unicamp.

Santos, T.C., \& Santiago, J. (2010). 0 médico, o psicanalista e a histérica: a desinserção da Psicanálise no discurso da Medicina contemporânea. In: J. Birman, I. Fortes \& S. Perelson. Um novo lance de dados. Psicanálise e Medicina na contemporaneidade (pp. 47-72). Rio de Janeiro: Cia de Freud.

Tomm, K. (1990). A critique of the DSM. Dulwich Centre Newsletter, 3. 